\title{
Field electron emission measurements as a complementary technique to assess carbon nanotube quality ${ }^{\circledR}$
}

Cite as: Appl. Phys. Lett. 116, 103101 (2020); https://doi.org/10.1063/1.5142346

Submitted: 12 December 2019 . Accepted: 22 February 2020 . Published Online: 09 March 2020

Mateus G. Masteghin (D), Muhammad Ahmad (iD), Mehmet O. Tas (D), Christopher T. C. Smith (D), Vlad Stolojan (D), David C. Cox (D), and S. Ravi P. Silva (D)

\section{COLLECTIONS}

EP This paper was selected as an Editor's Pick
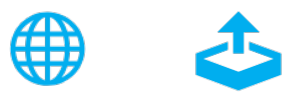

\section{ARTICLES YOU MAY BE INTERESTED IN}

\section{Epitaxial growth of rock salt $\mathrm{MgZrN}_{2}$ semiconductors on $\mathrm{MgO}$ and $\mathrm{GaN}$}

Applied Physics Letters 116, 102102 (2020); https://doi.org/10.1063/1.5140469

Thickness-dependent electron momentum relaxation times in iron films

Applied Physics Letters 116, 102406 (2020); https://doi.org/10.1063/1.5142479

Development of microLED

Applied Physics Letters 116, 100502 (2020); https://doi.org/10.1063/1.5145201

\section{Lock-in Amplifiers up to $600 \mathrm{MHz}$}
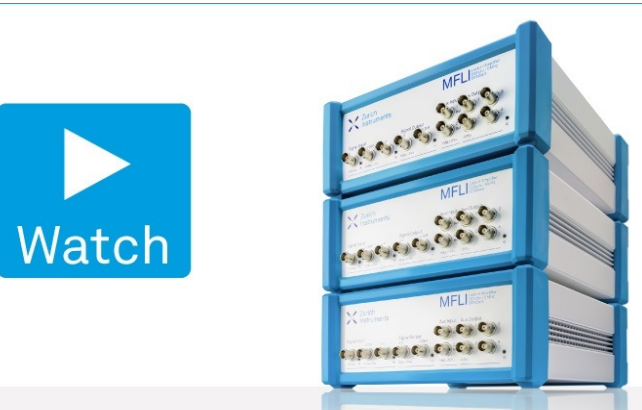


\title{
Field electron emission measurements as a complementary technique to assess carbon nanotube quality 라
}

\author{
Cite as: Appl. Phys. Lett. 116, 103101 (2020); doi: 10.1063/1.5142346 \\ Submitted: 12 December 2019 - Accepted: 22 February 2020 . \\ Published Online: 9 March 2020
}
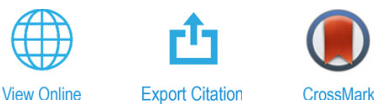

Mateus G. Masteghin, (D) Muhammad Ahmad, (D) Mehmet O. Tas, (iD Christopher T. G. Smith, (D) Vlad Stolojan, David C. Cox, (D) and S. Ravi P. Silva ${ }^{\text {a) }}$ (D)

\begin{abstract}
AFFILIATIONS
Advanced Technology Institute, Department of Electrical and Electronic Engineering, University of Surrey, Guildford GU2 7XH, United Kingdom
\end{abstract}

${ }^{a)}$ Author to whom correspondence should be addressed: s.silva@surrey.ac.uk

\begin{abstract}
Carbon nanotubes (CNTs) can be used in many different applications. Field emission (FE) measurements were used together with Raman spectroscopy to show a correlation between the microstructure and field emission parameters. However, field emission characterization does not suffer from fluorescence noise present in Raman spectroscopy. In this study, Raman spectroscopy is used to characterize vertically aligned CNT forest samples based on their $\mathrm{D} / \mathrm{G}$ band intensity ratio $\left(\mathrm{I}_{\mathrm{D}} / \mathrm{I}_{\mathrm{G}}\right)$, and FE properties such as the threshold electric field, enhancement coefficient, and anode to CNT tip separation (ATS) at the outset of emission have been obtained. A relationship between ATS at first emission and the enhancement factor, and, subsequently, a relationship between ATS and the $\mathrm{I}_{\mathrm{D}} / \mathrm{I}_{\mathrm{G}}$ are shown. Based on the findings, it is shown that a higher enhancement factor $(\sim 3070)$ results when a lower $\mathrm{I}_{\mathrm{D}} / \mathrm{I}_{\mathrm{G}}$ is present $(0.45)$, with initial emissions at larger distances $(\sim 47 \mu \mathrm{m})$. For the samples studied, the morphology of the CNT tips did not play an important role; therefore, the field enhancement factor $(\beta)$ could be directly related to the carbon nanotube structural properties such as breaks in the lattice or amorphous carbon content. Thus, this work presents FE as a complementary tool to evaluate the quality of CNT samples, with the advantages of a larger probe size and an averaging over the whole nanotube length. Correspondingly, one can find the best field emitter CNT according to its $\mathrm{I}_{\mathrm{D}} / \mathrm{I}_{\mathrm{G}}$.
\end{abstract}

Published under license by AIP Publishing. https://doi.org/10.1063/1.5142346

The introduction of carbon nanotubes (CNTs) to the scientific focus inspired the use of CNTs in countless applications, ${ }^{1}$ e.g., drug delivery, ${ }^{2}$ electronic, ${ }^{3}$ energy, ${ }^{4}$ mechanical, ${ }^{5}$ photodetector, ${ }^{6}$ sensor, and field emission applications. ${ }^{8,9}$ The chosen application depends on the CNT properties, such as high ballistic conduction for field effect transistors ${ }^{10}$ and high surface area and large aspect ratio for lithiumion-batteries. ${ }^{11}$ Other applications benefit from the well-known strength of CNTs such as nanotube-polymer structural composites. ${ }^{12}$ Furthermore, semiconducting CNTs can be used for organic vapor detection as a result of their 1-dimensional electronic structure. ${ }^{13}$ Finally, a low threshold voltage and long emitter lifetime allow CNTs to be used as cold electron sources. ${ }^{14}$ Therefore, with a wide range of both properties and applications, it is essential to accurately characterize the CNTs used.

Numerous methods are currently used to characterize CNTs, most commonly Raman spectroscopy. This method investigates the vibrational properties and electronic structures by means of laser excitation. ${ }^{15}$ Two noteworthy modes can be observed at around $1580 \mathrm{~cm}^{-1}$ and between 1330 and $1360 \mathrm{~cm}^{-1}$, the so-called $\mathrm{G}$ and D-bands, respectively. Coarsely, the G-band corresponds to the stretching mode in the graphite plane, while the D-band is associated with disorder or defect modes. ${ }^{16}$ Thus, the D/G band intensities $\left(\mathrm{I}_{\mathrm{D}} / \mathrm{I}_{\mathrm{G}}\right)$ can be used to evaluate the sample quality, in which a high-quality one, i.e., free of structural defects or amorphous carbon, will present a low $\mathrm{I}_{\mathrm{D}} / \mathrm{I}_{\mathrm{G}}$ ratio. ${ }^{17,18}$ In this work, we investigate the use of field emission (FE) as a complementary technique that can be used to characterize CNTs, with a larger scanned area. Moreover, considering that CNT forests are densely packed, Raman spectroscopy gives information mostly regarding the tips, ${ }^{19}$ while FE averages over the whole nanotube length. Another advantage of field emission is the low current density carried across the CNTs, not causing any change in its crystallinity. 
Field emission measurements consist of applying a large electric field between a metallic needle (anode) and the sample (cathode), which will result in electrons being emitted into the vacuum as a result of the charge carriers tunneling through a potential barrier to vacuum. Detailed studies of field emission through both theoretical modeling and experiment have been conducted in the past. ${ }^{20,21}$ The basics of this process were described by Fowler-Nordheim theory ${ }^{22}$ and consist of lowering the barrier height as a function of the increasing electric field, which increases the probability of a tunneling process. ${ }^{23,24}$ Thus, knowing that the potential barrier height and width are a function of sample defects and metal-semiconductor junction, it is sensible to combine the FE results with Raman spectroscopy. ${ }^{25}$ So far, many studies showed the field emission results for CNTs alongside TEM, ${ }^{14}$ $\mathrm{SEM}^{26}$ ab initio calculations, ${ }^{27} \mathrm{XPS},{ }^{28}$ and Raman, ${ }^{28}$ but only Ilie et al. ${ }^{29}$ showed a correlation between the techniques, relating the structure ( $s p^{2}$ clusters in amorphous carbon) and FE properties.

In this work, we associate the characteristic Raman peak intensities with Field Emission measurements. For instance, we demonstrate that the $\mathrm{I}_{\mathrm{D}} / \mathrm{I}_{\mathrm{G}}$ ratio can be correlated with the field enhancement coefficient $(\beta)$. Based on the findings reported in this study, we present an alternative approach to detect the CNT sample with the higher crystallinity (or smaller quantity of defects) just by means of finding the one that starts cold field emitting at the highest anode to CNT tip separation (ATS).

For the CNT growth, an $\mathrm{Al}(10 \mathrm{~nm}) / \mathrm{Fe}(3 \mathrm{~nm})$ catalyst layer structure was sputtered on $\mathrm{n}^{++} \mathrm{Si}$ substrates. The growth was carried out in a photo-thermal chemical vapor deposition (PTCVD) system ${ }^{30}$ at a substrate bulk temperature between $400^{\circ} \mathrm{C}$ and $430^{\circ} \mathrm{C}$, controlled by the electrical power supplied to the optical lamps, gas flow rate, and chamber pressure. In PTCVD, an array of eight lamps arranged in a circular geometry delivers optical energy directly to the top surface of the catalyst, while the sample is mounted on a water-cooled chuck. In this arrangement, a large temperature gradient is produced where the catalyst at the top surface of the sample reaches higher temperatures $\left(\sim 700^{\circ} \mathrm{C}\right)$, whereas the bulk of the sample remains at low temperatures. Samples were pre-heated in flowing $\mathrm{H}_{2}(100 \mathrm{sccm})$ for $10 \mathrm{~min}$ at 2 Torr followed by the CNT growth for 5 min using $50 \mathrm{sccm} \mathrm{C}_{2} \mathrm{H}_{2}$ as carbon feedstock.

Raman spectroscopy is employed to benchmark the quality of the as-deposited CNT forests with a spot size of $5 \mu \mathrm{m}$, a laser excitation energy of $514 \mathrm{~nm}(2.41 \mathrm{eV})$, and a $50 \times$ objective lens. In order to avoid damaging the CNTs, the power density of the laser is limited to below $100 \mu \mathrm{W} / \mu \mathrm{m}^{2}$. The scanned range is kept from 50 to $4000 \mathrm{~cm}^{-1}$ to include all first and second order resonance Raman features. Analysis is carried out by fitting Lorentzian functions to characteristic D and G peaks. ${ }^{29}$

Field emission measurements were carried out using seven samples containing vertically aligned multi-walled carbon nanotube (VAMWCNT) forest on $\mathrm{n}^{++} \mathrm{Si}$ substrates. For the measurements, the samples were inserted into the chamber and a vacuum of around $10^{-8} \mathrm{mbar}$ was established. A custom piezo-X, $\mathrm{Y}$, and, $\mathrm{Z}$ stage moved the tip against the samples, while a $500 \mathrm{~V}$ was applied by a power source (Keithley, model 248 High-Voltage Supply). The emission current is monitored using a current to voltage converter, in which a high input impedance operational-amplifier, type CA3140, is used to provide an output voltage in the range of $0-10 \mathrm{~V}$ for an input current in the range of $0-50 \mu \mathrm{A}$. The resulting voltage is monitored using a Keithley instruments type 195 digital multi-meter. After a current of $10 \mu \mathrm{A}$ was measured, the stage stopped $\left(\mathrm{z}_{0}\right)$ and the needle (anode) was pulled out by $300 \mu \mathrm{m}$, and then moved against the cathode by relative distances from $z_{0}$ of $+200,+150$, $+100,+50,+20,+10$, and $+5 \mu \mathrm{m}$. During all these different anodes to CNT tip separations (ATS), the power source was applied between 200 and $1500 \mathrm{~V}$ with steps of $2 \mathrm{~V}$, while collecting the data. Figure SI1 of the supplementary material presents a schematic drawing of the field emission kit, specifying the $\mathrm{W}^{0}$ anode needle diameter $(1 \mathrm{~mm})$ and the CNT sample size $\left(1 \times 1 \mathrm{~cm}^{2}\right)$. The approach to estimate the absolute distance between the $\mathrm{W}^{0}$ needle (anode) to the CNT tip, herein after called ATS, was also described.

The obtained $\mathrm{I}_{\mathrm{D}} / \mathrm{I}_{\mathrm{G}}$ ratios ranged from $0.45(\mathrm{~S} 1)$ to 0.65 (S7), with intermediate values of 0.48 (S2), 0.49 (S3 and S4), 0.50 (S5), and 0.52 (S6), as per Fig. 1(a). Given that the D band appears around
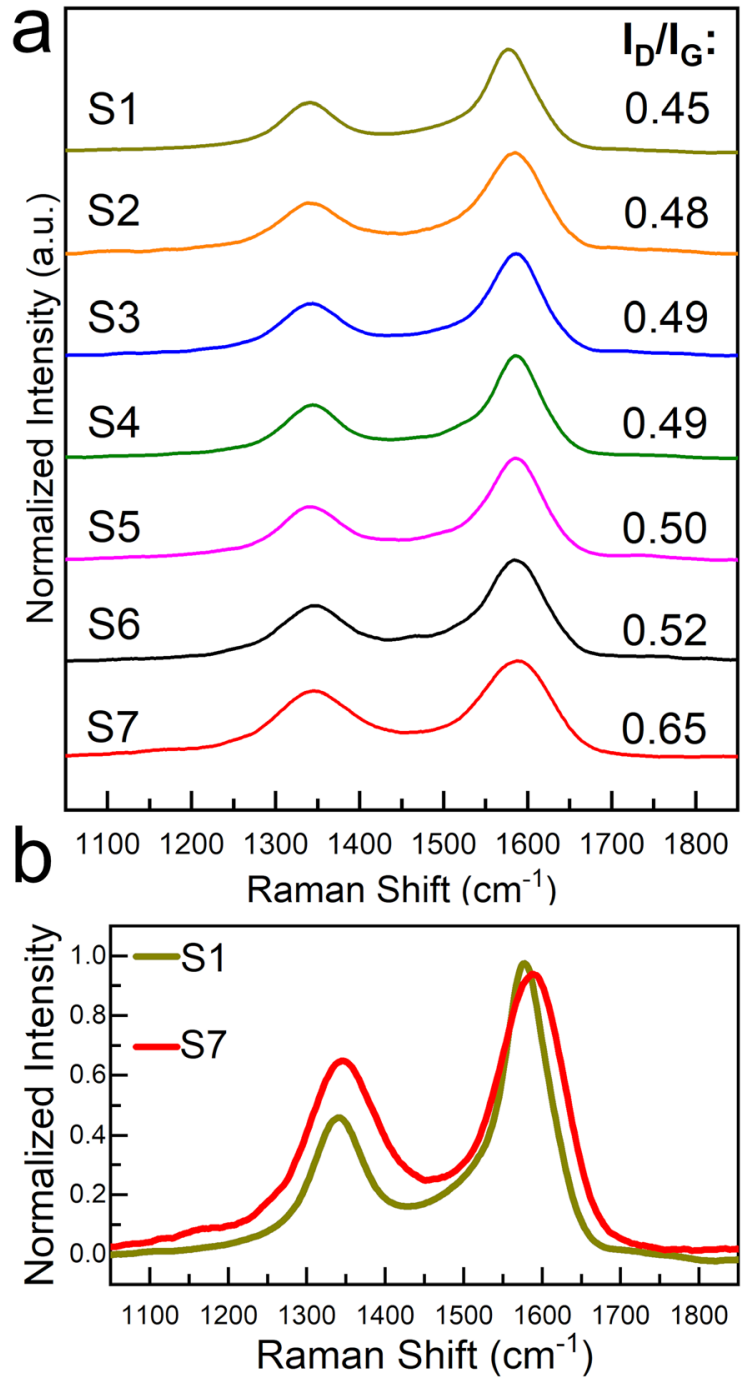

FIG. 1. (a) Normalized Raman spectra of the seven studied samples (S1-S7) grown under temperatures between $400^{\circ} \mathrm{C}$ and $430^{\circ} \mathrm{C}$. (b) Normalized Raman spectra of the highest and lowest quality samples (S1 and S7, respectively), focusing on the $D$ and $G$ bands. S1 has a lower D peak, and S7 has a larger FWHM of the $G$ peak. 
$1340 \mathrm{~cm}^{-1}$ and the $\mathrm{G}$ band is located around $1580 \mathrm{~cm}^{-1}$, from Fig. 1(b), it is found that the $\mathrm{I}_{\mathrm{D}} / \mathrm{I}_{\mathrm{G}}$ ratio of the highest quality sample (S1) is lower, while the opposite is true for the lowest quality one (S7). Moreover, the G band of S7 presents a larger full width at half maximum (FWHM) when compared to S1, confirming that S1 has a reduced number of defects. FWHMs of $\mathrm{S} 1$ and $\mathrm{S} 7$ are $66.8 \mathrm{~cm}^{-1}$ and $84.1 \mathrm{~cm}^{-1}$, respectively.

SEM images of the VA-MWCNT samples are given in Fig. SI2. The morphology of the CNT tips or their diameter distribution [around 5-10 nm, as per Fig. SI3(a)] does not appear to vary considerably. The CNTs for all growth conditions are homogeneously distributed over the $1 \times 1 \mathrm{~cm}^{2} \mathrm{Si}^{++}$substrate, and individual changes do not affect the $1 \mathrm{~mm}$ diameter scanned area. Besides that, no relationship between the VA-MWCNTs height and the obtained field emission properties was found. TEM images in Fig. SI3 show a multi-walled carbon nanotube (MWCNT) [Fig. SI3(b)], in agreement with Raman spectroscopy observations [no radial breathing modes (RBM), as per Fig. SI4].

Comparing the FE measurements in Figs. 2(a) and 2(b), it is evident that a lower electric field (E) is required for measurements on the highest quality sample [Fig. 2(a)] when compared to the E values in Fig. 2(b) (lowest quality MWCNT). It is also noteworthy that different emission currents were measured for the highest quality sample (S1) and the lowest quality one (S7), even using the same applied voltage. The lower emission current measured from S7 is even more pronounced at lowest electric fields.

The threshold electric field $\left(\mathrm{E}_{\mathrm{T}}\right)$, defined as the electric field required for a current density of $10 \mathrm{nA} \mathrm{cm}{ }^{-2}$, is also a function of the distance between the anode and the CNT tip (ATS). For the lowest quality sample (S7), $\mathrm{E}_{\mathrm{T}}$ is measured as $35.0 \mathrm{~V} \mu \mathrm{m}^{-1}$ at $10.58 \mu \mathrm{m}$ and $3.5 \mathrm{~V} \mu \mathrm{m}^{-1}$ at $310.58 \mu \mathrm{m}$, while these values decrease to $6.1 \mathrm{~V} \mu \mathrm{m}^{-1}$ at $46.76 \mu \mathrm{m}$ and $2.0 \mathrm{~V} \mu \mathrm{m}^{-1}$ at $346.76 \mu \mathrm{m}$ for the best quality MWCNT (S1). The results were obtained considering a $1 \mathrm{~mm}$ probe size and it is close to reported values. ${ }^{31}$

The threshold electric field $\left(\mathrm{E}_{\mathrm{T}}\right)$ itself can be used to evaluate the MWCNT defects, as shown that the $\mathrm{E}_{\mathrm{T}}$ should decrease as a function of the decreasing $\mathrm{I}_{\mathrm{D}} / \mathrm{I}_{\mathrm{G}}$ ratio. Thus, this method is also a nondestructive way to analyze the CNT quality with the advantage of a larger probe size when compared to the Raman spot size, allowing to have a more representative result in all 3 dimensions of the CNT forest ( $\mathrm{x}, \mathrm{y}$, and $\mathrm{z}$ ). It is shown that the CNT crystallinity can vary along a CNT, especially for long CNTs ( $>10 \mu \mathrm{m})$; nevertheless, Raman signal is collected only from the surface of a CNT film ${ }^{19}$ and it is also limited to a few micrometers spot size. If we consider per spot size measurement, field emission method could provide a more reliable ( $x, y$, and $\mathrm{z}$ ), faster (based on $1 \mathrm{~mm}$ spot size), and non-destructive measurement, free of fluorescence effect. Nonetheless, we will show that there is an easier way to study defects in CNTs using field emission measurements, without the need for significant analysis or data treatment.

Figure 3 shows a Fowler-Nordheim plot obtained from the field emission measurements. The natural logarithm of the $\left(\mathrm{I} / \mathrm{E}^{2}\right)$ vs $(1 / \mathrm{E})$ plot should be a straight line if the dominant process is the electron quantum tunneling through a potential barrier, ${ }^{32}$ as described by the following equation:

$$
I=\frac{a A \beta^{2} E^{2}}{\varnothing} * \exp \left(\frac{-b \varnothing^{3 / 2}}{\beta E}\right)
$$
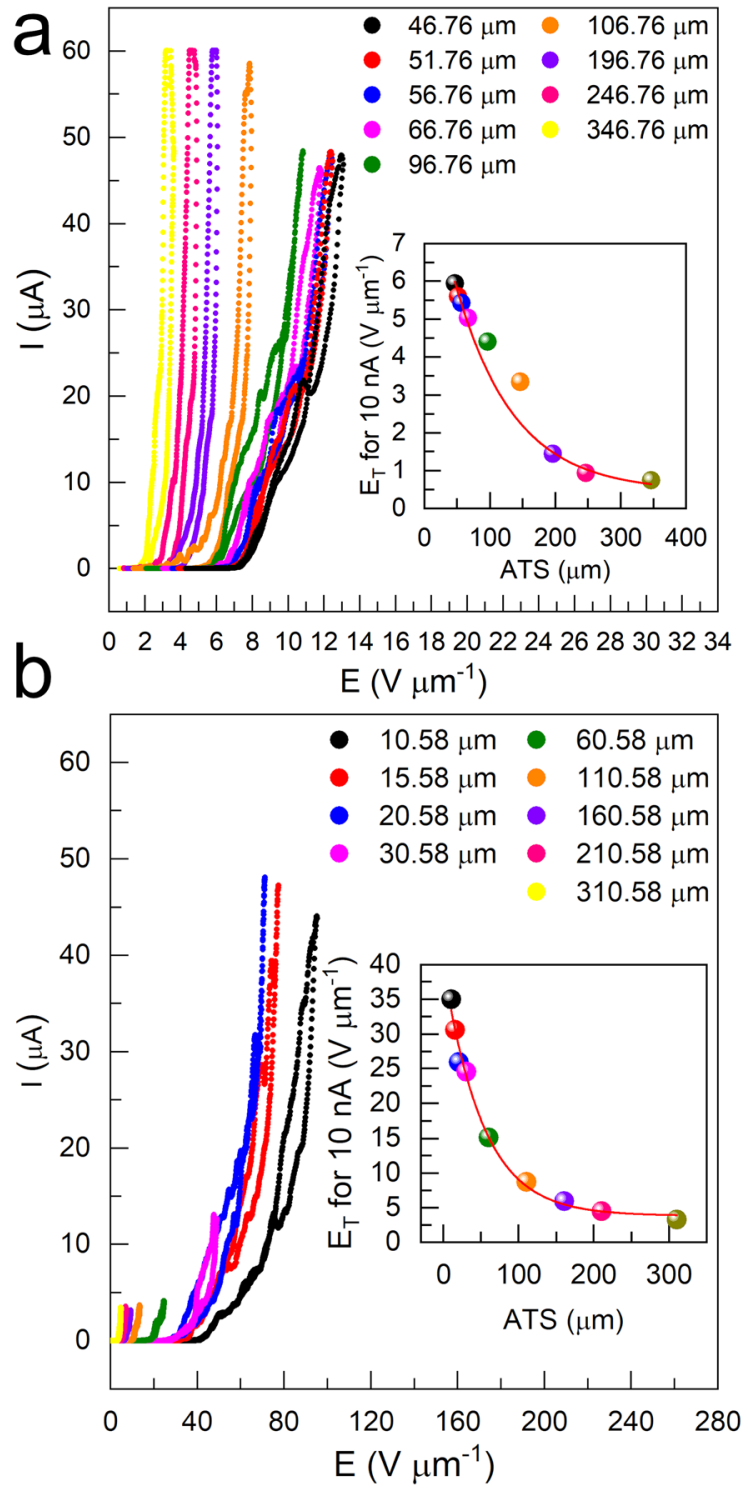

FIG. 2. Current (I) vs electric field (E) plots obtained from the field emission measurements showing different emission currents depending on the CNT quality. (a) Highest quality sample $\left(\mathrm{S} 1, \mathrm{I}_{\mathrm{D}} / \mathrm{I}_{\mathrm{G}}\right.$ equals to 0.45$)$ with first emission at $46.76 \mu \mathrm{m}$ $\left(z_{0}\right)$, and $\left.b\right)$ lowest quality sample $\left(S 7, I_{D} / l_{G}\right.$ equals 0.65$)$ with $z_{0}$ equaling $10.58 \mu \mathrm{m}$. The colors represent different anode to CNT tip separations (ATS). The inset of each graph show the exponential relationship between the threshold voltage $\left(E_{T}\right)$ and the anode to CNT tip separation (ATS), with a lower $E_{T}$ required for the highest quality CNT sample (S1). The I vs $E$ plot for sample $5\left(\mathrm{I}_{\mathrm{D}} / \mathrm{l}_{\mathrm{G}}\right.$ equals to 0.50 ) can be found in Fig. SI5, with $E_{T}$ ranging from $29.8 \mathrm{~V} \mu \mathrm{m}^{-1}$ at $12.54 \mu \mathrm{m}$ ATS to $3.2 \mathrm{~V} \mu \mathrm{m}^{-1}$ at $312.54 \mu \mathrm{m}$ ATS.

where $a$ and $b$ are constants equal to $1.54 \times 10^{-6} \mathrm{~A} \mathrm{eV} \mathrm{V}^{-2}$ and 6.83 $\times 10^{7} \mathrm{eV}^{3 / 2} \mathrm{~V} \mathrm{~cm}^{-1}$, respectively, ${ }^{33} \mathrm{~A}$ is the emission area, estimated to be $7.85 \times 10^{-3} \mathrm{~cm}^{-2}$ using a $1 \mathrm{~mm}$ diameter tungsten tip, $\varnothing$ is the work function (equal to $4.5 \mathrm{eV}$ ), ${ }^{33} \mathrm{I}$ is the measured current, and $\mathrm{E}$ is the applied electric field. Finally, $\beta$ is the enhancement factor, which is primarily related to the MWCNT morphology, but also depends on 


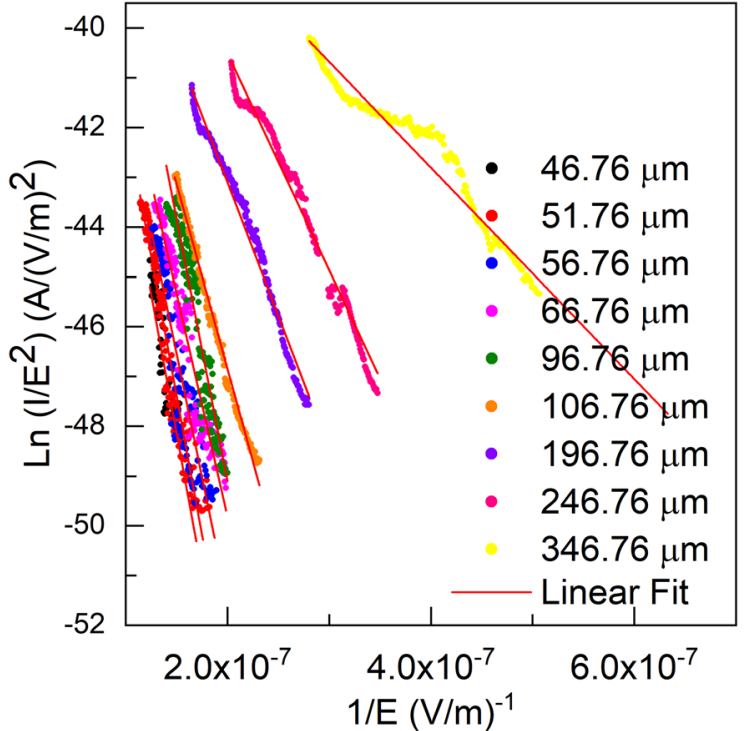

FIG. 3. Fowler-Nordheim plots at different anode to CNT tip separations (ATS) for the highest quality sample (S1, with $I_{D} / l_{G}$ equal to 0.45$)$. Dots are the experimental data and the continuous lines represent the linear fit used to obtain the enhancement factor $(\beta)$. The measurements at different ATS show the expected increase in the slope when moving from largest $(436.76 \mu \mathrm{m})$ to lowest $(46.76 \mu \mathrm{m})$ ATS. Fowler-Nordheim plots of $S 5\left(\mathrm{I}_{\mathrm{D}} / \mathrm{l}_{\mathrm{G}}\right.$ of 0.50$)$ and $\mathrm{S} 7\left(\mathrm{I}_{\mathrm{D}} / \mathrm{I}_{\mathrm{G}}\right.$ of 0.65$)$ can be found in Figs. SI6(a) and SI6(b), respectively.

the number of defects, e.g., broken $\mathrm{sp}^{2}$ bonds, kinks on the multiple walls of the CNTs, and the quantity of amorphous carbon. ${ }^{26,28,34}$

Based on Eq. (1), $\beta$ can be obtained from the slope of the curves in Fig. 3. Moreover, looking at Fig. 3, it is possible to see a decrease in the slope while increasing the distance between the electrodes, meaning a highest $\beta(3070)$ at the largest measured ATS $(346.76 \mu \mathrm{m})$. For this same sample (S1), an enhancement factor $(\beta)$ of 580 was obtained at $46.76 \mu \mathrm{m}$ ATS. Smith et al. ${ }^{33}$ and Passacantando et al. ${ }^{26}$ reported the same increase in the enhancement coefficient when the anode needle was moved away from the CNT tip, and, therefore, $\mathrm{E}_{\mathrm{T}}$ reduced asymptotically. This relationship between $\beta$ and $\mathrm{E}_{\mathrm{T}}$ is given by $\mathrm{E}_{\mathrm{FE}}$ $=\beta \mathrm{E}_{\mathrm{T}}$, in which $\mathrm{E}_{\mathrm{FE}}$ is the field at the top of the CNT tip and $\mathrm{E}_{\mathrm{T}}$ is defined as the applied potential (required for the field electron emission to occur) divided by ATS. When this so-called "far field condition" occurs (ATS $>3 \mathrm{~L}$, where L is the CNT length), ${ }^{26}$ the field emission properties are not a function of the ATS anymore, but rather of the CNT properties themselves, such as morphology and/or defects. This effect can be seen in the inset of Fig. 2(b), in which $\mathrm{E}_{\mathrm{T}}$ reaches a plateau around $110.58 \mu \mathrm{m}$ (for CNTs with a height equal to $42 \mu \mathrm{m}$ ).

Based on that, we collected the highest enhancement factors for each sample to show a relationship between the anode to CNT tip separation at first emission $\left(\mathrm{z}_{0}\right)$ and the extracted $\beta$ values at largest ATS $\left(\mathrm{z}_{0}+300 \mu \mathrm{m}\right)$, as can be seen in the blue plot of Fig. 4 .

In this study, the CNT tip morphology did not change among the seven samples, so the different enhancement factors $(\beta)$ obtained could only be attributed to the defects presented by each sample (D peak intensity). Thus, from Fig. 4, it is possible to infer that the ATS at first emission is exponentially related to the carbon nanotube

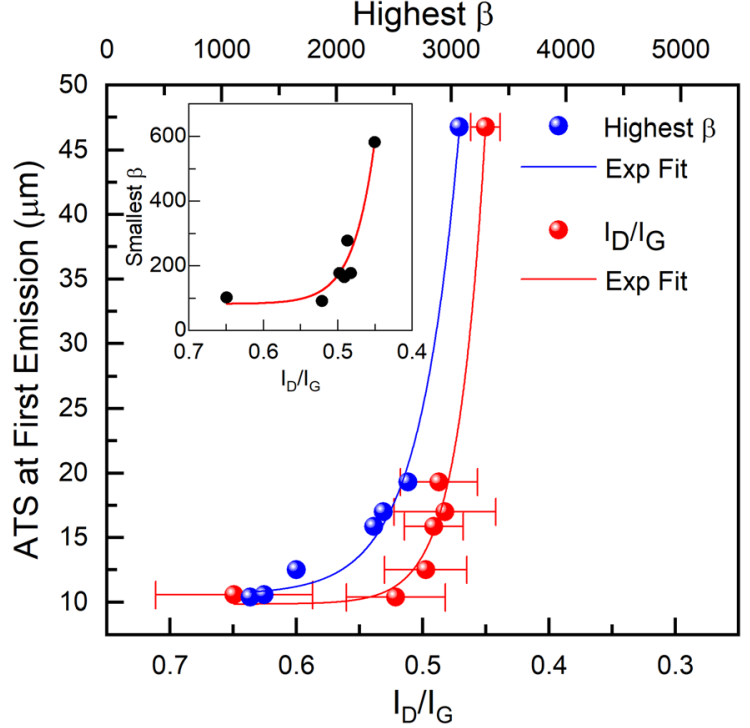

FIG. 4. The blue plot presents an exponential relationship between the highest enhancement factor $(\beta)$ and the anode to CNT tip separation (ATS) at first emission ( $\mathrm{z}_{0}$ value obtained for each sample). The presented $\beta$ values were extracted from the Fowler-Nordheim plot at largest ATS $\left(z_{0}+300 \mu \mathrm{m}\right)$. The red plot shows samples' $I_{D} / I_{G}$ (inverse scale, highest to lowest) vs ATS, with added error bars. The inset shows an exponential relationship between the obtained $\beta$ values at lowest ATS, and the inverse $I_{D} / l_{G}$, showing that the relationship between crystallinity and field electron emission properties is maintained regardless of the electric field used for the measurement.

properties, such as breaks in the lattice (structurally), and mainly the amount of amorphous carbon that are inherently defective.

Furthermore, a plot of ATS at first emission against $\mathrm{I}_{\mathrm{D}} / \mathrm{I}_{\mathrm{G}}$ allows to extract MWCNT structural properties based on the $z_{0}$ value obtained from the FE measurements. The red plot of Fig. 4 shows this exponential relationship between the ATS at first emission $\left(\mathrm{z}_{\mathrm{o}}\right)$ and the $\mathrm{I}_{\mathrm{D}} / \mathrm{I}_{\mathrm{G}}$ ratio obtained from the Raman measurements. As discussed in Fig. 1, a lower $I_{D} / I_{G}$ means a higher quality sample, with less defects and a higher crystallinity. ${ }^{18}$ Therefore, by comparing Raman and field emission measurements (with the Fowler-Nordheim approach to obtain $\beta$ ), it is possible to evaluate the carbon nanotube samples' quality only by comparing the distances required to measure a preestablished current using the same applied potential. Thus, the results show that a higher crystallinity sample ( $\mathrm{S} 1$ with a $\mathrm{I}_{\mathrm{D}} / \mathrm{I}_{\mathrm{G}}$ of 0.45 ) will start emitting at a higher ATS compared to a sample with more defects ( $\mathrm{S} 7$ with a $\mathrm{I}_{\mathrm{D}} / \mathrm{I}_{\mathrm{G}}$ of 0.65 ), agreeing with Ilie et al. ${ }^{29}$ who showed the influence of $s p^{2}$ clusters in the reduction of the $\mathrm{E}_{\mathrm{T}}$ in amorphous carbons. Endorsing this proposal, the same exponential relationship can be obtained between ATS at first emission and the FWMH of G Peak, in which S7 presented an FWHM of $84.1 \mathrm{~cm}^{-1}$ and the less defective S1 showed an FWHM of $66.8 \mathrm{~cm}^{-1} .35$

Moreover, the inset of Fig. 4 presents an exponential relationship between the smallest $\beta$ and the $\mathrm{I}_{\mathrm{D}} / \mathrm{I}_{\mathrm{G}}$ ratios plotted high to low on the $\mathrm{x}$-axis. This shows the field electron emission as a non-destructive characterization method, in which the relationship between enhancement factor (therefore CNT crystallinity) and decreasing $\mathrm{I}_{\mathrm{D}} / \mathrm{I}_{\mathrm{G}}$ was maintained as a function of increasing electric fields. 
In conclusion, we used two different techniques often used to characterize carbon nanotubes and found a correlation between them. Raman measurements allowed us to obtain the $\mathrm{I}_{\mathrm{D}} / \mathrm{I}_{\mathrm{G}}$ ratio of the MWCNT samples and the FWHM, while the Fowler-Nordheim plot gave us the enhancement factor, which is a function of the CNT structural properties, especially at the largest ATS (in this study, $\left.\mathrm{z}_{0}+300 \mu \mathrm{m}\right)$. Having established that, we can relate the $\beta$ values to the distance between the electrodes at first emission $\left(\mathrm{z}_{0}\right)$, furthermore finding a relationship between $\left(\mathrm{z}_{0}\right)$ and the $\mathrm{I}_{\mathrm{D}} / \mathrm{I}_{\mathrm{G}}$ ratio. Thus, this work shows that the field emission can be used as a complementary analysis to evaluate the number of defects or presence of amorphous carbon in a vertically aligned CNT forest sample with the advantage of a larger spot size and an averaging over the whole CNT length, without any fluorescence noise. On the other hand, Raman spectroscopy could be used to estimate which sample can be a better option as a field emitter. Besides, by keeping the CNT tip morphology constant, we presented a way in which field emission properties of CNTs could be tuned by controlling the amount of amorphous carbon by means of varying the synthesis temperature.

See the supplementary material for the details of the FE experiments and further characterization of the CNTs.

The authors would like to acknowledge Anthony R. Corless who wrote the FE Kit Software and kindly supported the experiments. The authors acknowledge financial support from EPSRC (Nos. EP/ L02263x/1 and EP/R025304/1) and the Brazilian Government FAPESP BEPE and SPRINT Programme for conducting this work.

\section{REFERENCES}

${ }^{\text {T} P . ~ M . ~ A j a y a n ~ a n d ~ O . ~ Z . ~ Z h o u, ~ C a r b o n ~ N a n o t u b e ~(S p r i n g e r, ~ 2001), ~ p p . ~ 391-425 . ~}$ ${ }^{2}$ P. Liu, Ind. Eng. Chem. Res. 52, 13517 (2013).

${ }^{3}$ S. Heinze, J. Tersoff, R. Martel, V. Derycke, J. Appenzeller, and P. Avouris, Phys. Rev. Lett. 89, 106801 (2002).

${ }^{4}$ A. J. Miller, R. A. Hatton, G. Y. Chen, and S. R. P. Silva, Appl. Phys. Lett. 90, 023105 (2007).

${ }^{5}$ A. Fakhru'l-Razi, M. A. Atieh, N. Girun, T. G. Chuah, M. El-Sadig, and D. R. A. Biak, Compos. Struct. 75, 496 (2006).

${ }^{6}$ A. D. Bartolomeo, F. Giubileo, A. Grillo, G. Luongo, L. Iemmo, F. Urban, L. Lozzi, D. Capista, M. Nardone, and M. Passacantando, Nanomaterials 9, 1598 (2019).
${ }^{7}$ Y. M. Wong, W. P. Kang, J. L. Davidson, A. Wisitsora-At, and K. L. Soh, Sens. Actuators, B 93, 327 (2003).

${ }^{8}$ K. Okano, S. Koizumi, S. R. P. Silva, and G. A. J. Amaratunga, Nature 381, 140 (1996).

${ }^{9}$ G. A. J. Amaratunga and S. R. P. Silva, Appl. Phys. Lett. 68, 2529 (1996).

${ }^{10}$ A. Javey, J. Guo, Q. Wang, M. Lundstrom, and H. Dai, Nature 424, 654 (2003).

${ }^{11}$ B. J. Landi, M. J. Ganter, C. D. Cress, R. A. DiLeo, and R. P. Raffaelle, Energy Environ. Sci. 2, 638 (2009).

${ }^{12}$ H. Koerner, G. Price, N. A. Pearce, M. Alexander, and R. A. Vaia, Nat. Mater. 3, 115 (2004).

${ }^{13}$ P. C. P. Watts, N. Mureau, Z. Tang, Y. Miyajima, J. D. Carey, and S. R. P. Silva, Nanotechnology 18, 175701 (2007).

${ }^{14}$ Y. Saito and S. Uemura, Carbon 38, 169 (2000).

${ }^{15}$ E. F. Antunes, A. O. Lobo, E. J. Corat, V. J. Trava-Airoldi, A. A. Martin, and C. Veríssimo, Carbon 44, 2202 (2006).

${ }^{16}$ A. C. Ferrari and J. Robertson, Phys. Rev. B 61, 14095 (2000).

${ }^{17}$ J. Schwan, S. Ulrich, V. Batori, H. Ehrhardt, and S. R. P. Silva, J. Appl. Phys. 80, 440 (1996).

${ }^{18}$ M. S. Dresselhaus, G. Dresselhaus, R. Saito, and A. Jorio, Phys. Rep. 409, 47 (2005).

${ }^{19}$ H. Nii, Y. Sumiyama, H. Nakagawa, and A. Kunishige, Appl. Phys. Express 1, 064005 (2008).

${ }^{20}$ A. D. Bartolomeo, A. Scarfato, F. Giubileo, F. Bobba, M. Biasiucci, A. M. Cucolo, S. Santucci, and M. Passacantando, Carbon 45, 2957 (2007).

${ }^{21}$ L. D. Filip, J. David Carey, and S. R. P. Silva, J. Appl. Phys, 109, 84527 (2011).

${ }^{22}$ R. H. Fowler and L. Nordheim, Proc. R. Soc. London, Ser. A 119, 173 (1928).

${ }^{23}$ J. Maserjian and N. Zamani, J. Appl. Phys. 53, 559 (1982).

${ }^{24}$ M. Lenzlinger and E. H. Snow, J. Appl. Phys. 40, 278 (1969).

${ }^{25}$ R. T. Tung, Appl. Phys. Rev. 1, 11304 (2014).

${ }^{26}$ M. Passacantando, F. Bussolotti, S. Santucci, A. D. Bartolomeo, F. Giubileo, L. Iemmo, and A. M. Cucolo, Nanotechnology 19, 395701 (2008).

${ }^{27}$ Y.-W. Son, S. Oh, J. Ihm, and S. Han, Nanotechnology 16, 125 (2005).

${ }^{28}$ K. S. Hazra, N. A. Koratkar, and D. S. Misra, Carbon 49, 4760 (2011).

${ }^{29}$ A. Ilie, A. C. Ferrari, T. Yagi, and J. Robertson, Appl. Phys. Lett. 76, 2627 (2000).

30 J. V. Anguita, D. C. Cox, M. Ahmad, Y. Y. Tan, J. Allam, and S. R. P. Silva, Adv. Funct. Mater. 23, 5502 (2013).

${ }^{31}$ M. Sveningsson, R.-E. Morjan, O. A. Nerushev, Y. Sato, J. Bäckström, E. E. B. Campbell, and F. Rohmund, Appl. Phys. A 73, 409 (2001).

${ }^{32}$ W.-C. Chang, C.-H. Kuo, C.-C. Juan, P.-J. Lee, Y.-L. Chueh, and S.-J. Lin, Nanoscale Res. Lett. 7, 684 (2012).

${ }^{33}$ R. C. Smith, D. C. Cox, and S. R. P. Silva, Appl. Phys. Lett. 87, 103112 (2005).

${ }^{34}$ C. Y. Zhi, X. D. Bai, and E. G. Wang, Appl. Phys. Lett. 81, 1690 (2002).

${ }^{35}$ S. S. Mahajan, M. D. Bambole, S. P. Gokhale, and A. B. Gaikwad, Pramana 74, 447 (2010). 